\title{
Project 1019085
}

\section{Influence of Reactive Transport on the Reduction of $\mathrm{U}(\mathrm{VI})$ in the Presence of $\mathrm{Fe}(\mathrm{III})$ and Nitrate: Implications for $\mathrm{U}(\mathrm{VI})$ Immobilization by Bioremediation/Bioba}

\author{
Wood, Brian D. \\ Oregon State University
}

\begin{abstract}
RESULTS TO DATE: The research in FY04 was focused in five specific topics: (1) U(VI) sorption on microbially and abiotically reduced sediments, (2) oxidation of biogenic $U(I V)$ in presence of $\mathrm{Fe}(\mathrm{II}),(3) \mathrm{U}(\mathrm{VI})$ reduction by reduced sediments, (4) kinetics of $\mathrm{U}(\mathrm{VI})$ sorption on natural sediments under conditions of flow, and (5) NMR imaging of $\mathrm{S}$. onidensis biofilms in porous media. Two manuscripts are currently in review, and another five (or four?) manuscripts are currently in preparation for submission.
\end{abstract}

1. $\mathrm{U}(\mathrm{VI})$ sorption on microbially and abiotically reduced sediments. Sorption of $\mathrm{U}(\mathrm{VI})$ by subsurface sediments is a primary process that immobilizes $\mathrm{U}(\mathrm{VI})$ without reductive reaction. It is also a prerequisite for indirect microbial reduction of $\mathrm{U}(\mathrm{VI})$ through intermediate redox pair, $\mathrm{Fe}(\mathrm{III}) / \mathrm{Fe}(\mathrm{II})$. The rate and extent of $\mathrm{U}(\mathrm{VI})$ sorption will therefore affect reactive transport and overall (direct and indirect) rate of microbial reduction of $\mathrm{U}(\mathrm{VI})$. In this study, we have investigated $\mathrm{U}(\mathrm{VI})$ sorption to sediments before and after microbial reduction by Shewanella putrefaciens $\mathrm{CN} 32$. $\mathrm{U}(\mathrm{VI})$ sorption to the sediments abiotically reduced with dithionite-citrate-bicarbonate, DCB, was also studied for comparison. The sediments from DOE NABIR field research center $(\mathrm{FRC})$ at Oak Ridge site were used. $\mathrm{U}(\mathrm{VI})$ sorption edges, sorption kinetics, and sorption extents were experimentally determined in batch system. The phase changes of iron minerals as primary $\mathrm{U}(\mathrm{VI})$ sorbents before and after sediment reduction were monitored by Mossbauer spectroscopy. Several surface complexation-based $\mathrm{U}(\mathrm{VI})$ adsorption models were tested to interpret the experimental results. Major findings from this study include: 1 ) both rate and extent of $\mathrm{U}(\mathrm{VI})$ sorption was not affected by the sediment microbial reduction under wide range conditions of $\mathrm{pH}$, carbonate and $\mathrm{U}(\mathrm{VI})$ concentrations; 2) The sediments with DCB treatment, which removed all iron oxides, significantly decreased $\mathrm{U}(\mathrm{VI})$ sorption; 3) $\mathrm{U}(\mathrm{VI})$ reduction by Fe(II) that was adsorbed to the microbially reduced FRC sediments was negligible; and 4) at least two kinds of sorption sites with weak and strong complexation reactions were needed to model the experimental results. The results from this study implied that a unified two-site $\mathrm{U}(\mathrm{VI})$ surface complexation model with the same set of reaction constants was able to describe $U(\mathrm{VI})$ sorption to the pristine and bioreduced FRC sediments. A manuscript has been submitted to Environmental Science and Technology.

2. Oxidation of biogenic $\mathrm{U}(\mathrm{IV})$ in presence of $F(\mathrm{II})$. Fresh biogenic $\mathrm{U}(\mathrm{IV})$ is readily oxidized if exposed to $\mathrm{O} 2$ that could be carried by oxygenated groundwater when a remediated subsurface environment returns to oxic condition. Maintaining stability of immobilized uranium is critical for the success using microbial reduction as a long term remediation technology. In this study, we have investigated the role of $\mathrm{Fe}(\mathrm{II})$ in enhancing the stability of immobilized biogenic uranium in microbially reduced FRC sediments. Fe(II) is a typical by-product of microbial reduction of $\mathrm{U}(\mathrm{VI})$ because of ubiquitous presence of iron oxides as an alternative electron acceptor for metal reducing bacteria. The influence of $\mathrm{CO} 2, \mathrm{pH}, \mathrm{Fe}(\mathrm{II})$ concentration, and aging of biogenic $\mathrm{U}$ (IV) on the rate and extent of biogenic $\mathrm{U}(\mathrm{VI})$ remobilization was also studied. Our results showed that the presence of $\mathrm{Fe}$ (II) under all conditions could significantly decrease the rate and extent of uranium remobilization. The observed stability of uranium immobilization increased with increasing $\mathrm{Fe}(\mathrm{II})$ concentration and affected by other geochemical conditions such as $\mathrm{pH}$ and carbonate concentration. The results implied that biogeochemical conditions in subsurface sediments may be manipulated to maximize long-term stability of immobilized uranium. A manuscript has been submitted to Science of Total Environment from this study. 
3. $\mathrm{U}(\mathrm{VI})$ reduction by microbially and abiotically reduced sediments. It is well known that $\mathrm{U}(\mathrm{VI})$ could be directly reduced by metal reducing bacteria. There was a report in literature that hematite surface bounded $\mathrm{Fe}(\mathrm{II})$ could reduce $\mathrm{U}(\mathrm{VI})$, implying that $\mathrm{U}(\mathrm{VI})$ may be indirectly reduced in subsurface environment by metal reducing bacteria through intermediate redox pair, $\mathrm{Fe}(\mathrm{III}) / \mathrm{Fe}(\mathrm{II})$. In order to examine this indirect reduction process in natural sediments, we have studied $\mathrm{U}(\mathrm{VI})$ reduction by Fe(II)-spiked DCB reduced and biogenic Fe(II) associated bioreduced FRC sediments. Our results indicated, however, that the reduced FRC sediments was either not able to reduce $\mathrm{U}(\mathrm{VI})$ or the extent of reduction was below detection limit. This is in contrast to the literature report and implies that this abiotic reduction of $\mathrm{U}(\mathrm{VI})$ may be negligible compared with enzymatic way for FRC sediments. The result implied that direct enzymatic reduction of $\mathrm{U}(\mathrm{VI})$ is required in the FRC sediments to reductively immobilize uranium. The mechanism for this contrast is still unclear and needs further investigation.

4. Kinetics of $\mathrm{U}(\mathrm{VI})$ sorption on natural sediments under conditions of flow. Sorption experiments have been conducted under flowing conditions to determine the $\mathrm{U}(\mathrm{VI})$ sorption rate to (Fe-oxides, or natural sediments under two carbonate concentrations (1 and $10 \mathrm{mmol} / \mathrm{L}$ ) and a range of $\mathrm{pH}$ values (4-9). Carbonates can form complexes with $\mathrm{U}(\mathrm{VI})$, and these complexes appear to adsorb most strongly at circumneutral $\mathrm{pH}$. Previous work by other NABIR researchers (S. Brooks) has reported the equilibrium sorption isotherms for $\mathrm{U}(\mathrm{VI})$ in batch systems. We are extending this work to examine the importance of the kinetics of $\mathrm{U}(\mathrm{VI})$ sorption under conditions of transport. Our experiments have been conducted using DOE site sediments (Hanford) at groundwater velocities relevant to field remediation. The systems have been constructed at intermediate scale (50 cm long) and using artificial groundwaters that approximate geochemical conditions found at Hanford and at the FRC. Our results so far indicate that the sorption of $U(\mathrm{VI})$ in natural sediments under flow condition cannot be treated as an equilibrium process. This is an important observation, because it indicates that under conditions that apply to bioremediation, it may not be possible to assume equilibrium partitioning of $\mathrm{U}(\mathrm{VI})$ species to the solid phase. We are currently assessing whether the sorption is a diffusion- or rate-limited process. One manuscript is currently in process on this work.

5. NMR imaging of S. onidensis biofilms in porous media. In Task 2 of the proposed work, a set of experiments are described in which confocal microscopy was to be used to examine biofilm formation in 2-dimensional systems; this work was designed to help assess how important mass transfer resistance through biofilms might be in the formation of anaerobic microsites and the process of metal reduction. Recently, new nuclear magnetic resonance (NMR) instruments have become available at the Environmental Molecular Sciences Laboratory (EMSL) that can, in principle, accomplish the same result but in a more-physically-relevant 3-dimensional format. Several blocks of user time have been requested (by B. Wood), supported at no cost to the project as part of the EMSL?s user facility mission. We have now conducted several experiments of the use of NMR for non-destructive measurement of growing biofilms of Shewanella onidensis MR-1 in porous media. Our most recent results have provided images of MR-1 in the pore space of a $3 \mathrm{~mm}$ diameter by $8 \mathrm{~mm}$ long tube filled with $0.25 \mathrm{~mm}$ diameter porous media. The organisms were grown aerobically in the NMR annulus, and the fully developed biofilms and porous media was imaged at a resolution of 30 micrometers by 30 micrometers by 30 micrometers. The image was collected with the intent of recovering local diffusion coefficients to be used as a filter to distinguish biofilm from fluid. Our most recent experiments have been successful, and remarkable images of MR-1 biofilm in porous media have been obtained at an unprecedented resolution. We have one manuscript that has been published on this work.

6. Metabolic Decouplers. The theme of our research has been focused on the role of flow and transport on (1) promoting and sustaining metal reduction in the subsurface, and (2) the minimization of reoxidation of U(IV) mineral phases. At the 2004 NABIR PI meeting, there was vigorous discussion about the failures that can be encountered in bioremediation caused by microbial overgrowth near injection wells. The problems created by the uncontrolled growth of bacteria near points of substrate injection was identified as a fundamental problem for which 
additional research is desperately needed. Our ongoing research has been focused on the role of mass fluxes of substrates, electron acceptors, and other aqueous species (such as Fe(II)) on establishing and maintaining bioremediation by biobarriers. Because our work has been closely aligned with questions regarding the control of microbial growth, in our final year we had begun to explore the potential use of metabolic decoupling agents for subsurface bioremediation. This proposal seeks ?close out? funding to complete this work. The basis of this research has been centered on the following hypothesis. Hypothesis. The use of chemical metabolic uncouplers can be used in subsurface bioremediation schemes to shunt energy (carbon) to catabolic pathways, and maximize electron transfer while minimizing additional microbial growth.

One student has begun work on this area, and will complete this research if close-out funding is awarded.

7. Student Presentation. Finally, we would like to report that we have one student who presented research results from this project at the December 2003 American Geophysical Union meeting.

\section{Summary.}

The collaboration between researchers at OSU and PNNL on this project has been very positive, and graduate students from OSU have visited PNNL to work with researchers there on projectrelated work several times. Additionally, all researchers on this project have been able to meet at PNNL at least 3 times over the calendar year to discuss project progress and directions. We are looking forward to continuing these collaborations on this research area.

DELIVERABLES: A total of nine papers have been published in peer-reviewed journals (or books) or are currently in review. Each of the following papers explicitly acknowledges this project for all or part of its funding.

1. Liu C., Zhong L., Zachara J.M., Kukkadupa R., Szecsody J.E., and Kennedy D.W., 2004. Abiotic interactions of $\mathrm{U}(\mathrm{VI})$ with microbially reduced sediments, manuscript submitted to Environmental Science and Technology.

2. Zhong, L., Liu, C., Zachara, J.M., Kennedy, D., Szecsody, J.E., and Wood, B.D., 2004. Oxidative dissolution of biogenic U(IV) precipitates: Effects of $\mathrm{Fe}(\mathrm{II})$ and $\mathrm{pH}$. Manuscript submitted to Journal of Contaminant Hydrology.

3. Wood, B.D. Golfier, F., Majors, P., Quintard, M., and Whitaker, S., 2004. Biofilms in porous media: Upscaling conservation equations and measurement of microbial distributions via NMR, submitted to Water Science and Technology.

4. Szecsody, J., Fructer, J.S., Williams, M.D., Vermeul, V.R., and Sklarew, D., 2004. In situ chemical reduction of aquifer sediements: Enhancement of reactive iron phases and TCE dechlorination. Environmental Science and Technology, 38: 4656-4663.

5. Wood, B.D., Whitaker, S., and Quintard, M. 2004. Estimation of adsorption coefficients on the basis of the Smoluchowski Equation, Chemical Engineering Science, doi:10.01016/j.ces.2003.12.021.

6. Wood, B.D., F. Cherblanc, M. Quintard, and S. Whitaker, 2003. Volume averaging for determining the effective dispersion tensor: Closure using periodic unit cells and comparison with ensemble averaging, Water Resour. Res., 39(8), 1210, doi:10.1029/2002WR001723. 
7. Wood, B.D., Quintard, M., Golfier, F. and Whitaker, S., 2002, Biofilms in Porous Media: Development of Macroscopic Transport Equations via Volume Averaging with Closure, in Computational Methods in Water Resources, vol. 2, 1195-1202, edited by S.M. Hassanizadeh, R.J. Schotting, W.G. Gray and G.F. Pinder, Elsevier, Amsterdam.

8. Ginn, T.R., B.D. Wood, K.E. Nelson, T.D. Scheibe, E.M. Murphy, and T.P. Clement, 2002. ?Processes in Microbial Transport in the Natural Subsurface,? Advances in Water Resources. 25:1017-1042.

9. Scheibe, T.D., and B.D. Wood, A particle-based model of size or anion exclusion with application to microbial transport in porous media, Water Resour. Res., 39(4), 1080, doi:10.1029/2001WR001223, 2003.

COLLABORATIONS: Collaborations with Prof. Jack Istok, also a NABIR PI at OSU.

Collaborations will be on analysis of push-pull tests, and $\mathrm{U}(\mathrm{VI})$ reduction in situ at the FRC field site. We will co-advise 1 graduate student working in this area, and encourage our all of our students working on $\mathrm{U}(\mathrm{VI})$ transport and reduction processes to interact with one another and to exchange information. 